\title{
Targeted screening programmes in COPD: how to identify individuals with $\alpha_{1}$-antitrypsin deficiency
}

\author{
Joanna Chorostowska-Wynimko
}

Affiliation: Dept of Genetics and Clinical Immunology, National Institute of Tuberculosis and Lung Diseases, Warsaw, Poland.

Correspondence: Joanna Chorostowska-Wynimko, Dept of Genetics and Clinical Immunology, National Institute of Tuberculosis and Lung Diseases, Warsaw, Poland. E-mail: j.chorostowskaQaigichp.edu.pl

ABSTRACT $\alpha_{1}$-antitrypsin deficiency (AATD) is a significantly under-recognised autosomal genetic disorder with $<10 \%$ of affected individuals being clinically diagnosed. Moreover, rigorous genetic epidemiological data regarding AATD are lacking. The majority of findings come from the USA and Western Europe, and no information is available for many countries. To address this concern, an $\alpha_{1^{-}}$ antitrypsin (AAT) laboratory was set up in 2009 at the National Institute of Tuberculosis and Lung Diseases (Warsaw, Poland). In 2010, an AATD screening programme targeting patients with respiratory disorders was initiated in Poland. This targeted survey has provided valuable information regarding AATdeficient genotypes, clinical disease and levels of expertise at the physician level. After 4 years, almost 2500 patients with chronic obstructive pulmonary disorders have been screened and, in this cohort, $13 \%$ had AATD alleles. In these patients, the detection frequency for $S$ and $Z$ alleles was four times greater, and the frequency of homozygous $\mathrm{PI}^{\star} \mathrm{ZZ}$ was 16 times greater than that of the general population. These results highlight the need to build awareness in the medical community, and the project is currently being extended to cover central Eastern Europe, with the creation of the Central Eastern European Alpha-1 Antitrypsin Network.

@ERSpublications

Effective screening and diagnostic strategies for AATD are being implemented across central Eastern Europe http://ow.ly/H9Ibf

\section{Introduction}

$\alpha_{1}$-antitrypsin deficiency (AATD) is one of the most common autosomal genetic disorders in humans, although it is still considered a rare recessive hereditary disorder and is significantly underdiagnosed [1-3]. Clinically, AATD is associated with an increased risk for chronic obstructive pulmonary disease (COPD). Protease inhibitor M (medium mobility) is the normal allele and a large number of genetic variants of $\alpha_{1}$-antitrypsin (AAT) have been identified (possibly in excess of 100) [4].

At present there is a lack of rigorous genetic epidemiological data regarding AATD; the majority of findings come from the USA and Western Europe with no information available for 50\% of the 193 countries [4]. This situation impedes our ability to fully understand the true prevalence of this disorder in many populations worldwide. Further hindering our understanding of the disease and its genetic distribution are low levels of accurate diagnosis, with rates of $\leqslant 5 \%$ reported in a number of countries [4-6].

Received: Nov 132014 | Accepted after revision: Dec 152014

Conflict of interest: Disclosures can be found alongside the online version of this article at err.ersjournals.com

Provenance: Publication of this peer-reviewed article was supported by Grifols, Barcelona, Spain (article sponsor, European Respiratory Review issue 135).

Copyright OERS 2015. ERR articles are open access and distributed under the terms of the Creative Commons Attribution Non-Commercial Licence 4.0. 


\section{AATD prevalence in Europe}

Analyses of AAT gene frequencies across Europe indicate a striking difference between Western and central Eastern European regions [7]. In figure 1, the distributions across Europe of the two most frequent deficiency alleles $\mathrm{PI}^{\star} \mathrm{S}$ and $\mathrm{PI}^{\star} \mathrm{Z}$ are shown. However, due to the lack of data in many countries, some distribution rates were calculated by an interpolation approach and, therefore, these should only be regarded as estimates. Thus, the differences in prevalence rates for AATD between Western and Eastern Europe most likely reflect existing published data, which is poor for many countries, rather than a real difference. To investigate this hypothesis, we performed a literature search for peer-reviewed publications investigating epidemiological data regarding AATD in European countries. We identified 150 publications for Western European countries and 27 publications for central Eastern European countries (six countries had no published data). This reinforces the hypothesis that the difference in gene frequency rates between Western and central Eastern Europe in relation to the prevalence of AATD subtypes is most likely due to a lack of rigorous epidemiological data, rather than a real difference between neighbouring countries, and highlights the need for better screening studies. Prior to 2007, five studies in Poland had been published, but these studies were all in relatively small populations and did not provide the quality of data required to ascertain accurate prevalence rates for deficiency alleles $[8,9]$.

\section{Improving AATD detection in Poland}

In 2009, an AAT laboratory was set up at the National Institute of Tuberculosis and Lung Diseases (Warsaw, Poland) and funding was obtained from the Polish Ministry of Science and Higher Education (Warsaw) to perform an AAT epidemiological study to determine the true prevalence rate of AAT alleles in the Polish population. In 2010, a large-scale population study was initiated which involved the screening of consecutive newborns at four centres in central Poland [10]. To date, almost 5000 children have been screened. The prevalence of the $\mathrm{PI}^{\star} \mathrm{S}$ allele has been shown to be lower than previously reported, whereas the prevalence of the $\mathrm{PI}^{\star} \mathrm{Z}$ allele is much higher [11]. Consequently, $\mathrm{ZZ}$ homozygosity is also much higher than previously thought in the general Polish population, as is the number of patients with severe AATD. When the project began, only three patients had a diagnosis of AATD in Poland $(<0.1 \%$ of the AATD population). Although this number had increased 10 -fold to $\sim 1 \%$ (37 patients) in 2014 , it is still quite low and indicates that $99 \%$ of AATD patients in Poland remain undiagnosed. The USA and countries in Western Europe have identified more patients with AATD $(\sim 2.4 \%)$, which is to be expected given the longer time period of active screening, yet the number undiagnosed is still very large [6].

In 1997 the World Health Organization published a position paper on AATD which included recommendations for testing all COPD patients from areas with a particularly high prevalence of AATD [12]. In 2003 the American Thoracic Society/European Respiratory Society published guidelines for the diagnosis of AATD [13]. Type A recommendations for diagnosing AATD include evaluating symptomatic patients with emphysema, COPD or bronchial asthma who have persistent obstruction on pulmonary function testing and also asymptomatic individuals with identifiable risk factors such as smoking or occupational exposure who have persistent obstruction on pulmonary function testing [13]. These guideline recommendations are highly specific. And yet, the question arises as to why we are not able to identify and treat more patients with AATD? As part of the development of a screening programme in Poland we investigated the existing published data to see if any answers to this question could be found. A

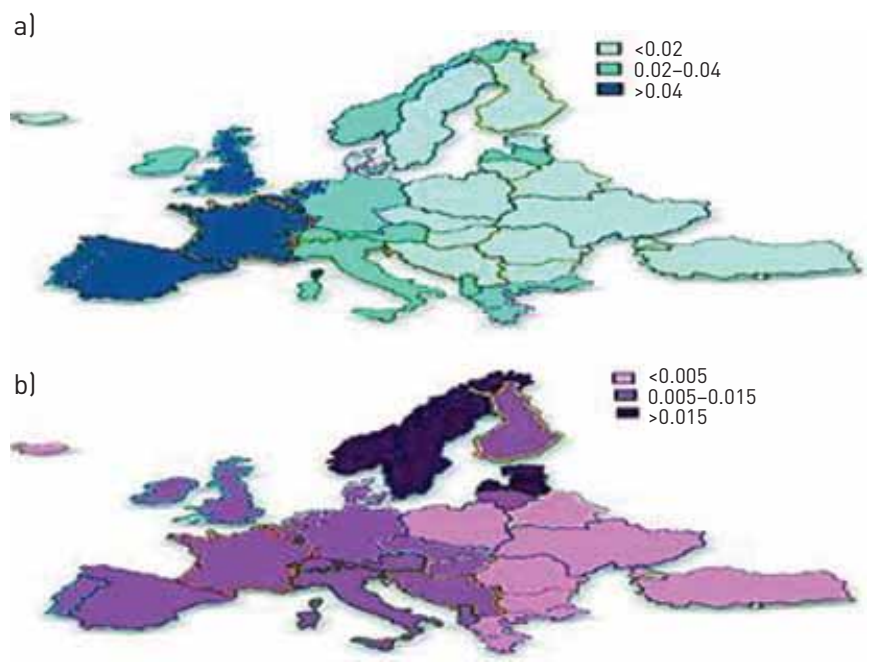

FIGURE 1 - $\alpha_{1}$-antitrypsin deficiency a) $\mathrm{PI}^{\star} \mathrm{S}$ and b) $\mathrm{PI}^{\star} \mathrm{Z}$ gene frequency distribution across Europe. Reproduced from [1] with permission from the publisher. 
number of screening studies were compared to assess the methods used and to correlate these with the results obtained.

The first screening study evaluated was a primary care study involving 1060 patients with COPD, asthma, bronchiectasis or emphysema [14]. The findings were disappointing with a low number of positive results obtained by phenotyping of dry blood spot samples, possibly due to the wide inclusion criteria and the lack of well-defined lung function criteria.

Better results were obtained by DE LA ROzA et al. [15] in a two-phase study involving COPD patients in Spain. The first phase analysed samples from 971 patients to determine AAT levels and identify the deficient $Z$ allele by genotyping using rapid real-time PCR. The second phase analysed AAT concentrations in 1166 samples and identified both the $S$ and $Z$ alleles, but only in samples with low AAT concentrations. Well-defined inclusion criteria with lung function testing was employed, and a cut-off point for AAT of $1 \mathrm{~g} \cdot \mathrm{L}^{-1}$ ensured that this was an efficient and cost-effective diagnostic algorithm [15].

A final study, and one which influenced the way that we organised the Polish screening programme, was published by BALS et al. [16]. This group undertook a targeted screening programme, which involved increasing AATD awareness in the medical community through a mailing initiative. The results of this study showed that the combination of an awareness programme with the offer of free diagnostic testing resulted in the identification of a large number of individuals with severe AATD. Overall, from 2722 submitted kits, 335 patients ( $\sim 12 \%$ of all samples) with severe AATD were identified, including 16 individuals with rare genotypes [16].

\section{AATD diagnosis and screening}

\section{Poland}

In 2010 two AATD screening programmes were initiated in Poland: one in patients with severe liver disease [17] and one targeted at patients with respiratory disorders, which is still ongoing and will be the focus of this section [18]. The patients in the respiratory programme were required to have a persistent obstructive disorder confirmed by spirometry. The diagnostic algorithm was relatively simple in that diagnostic kits were supplied to all physicians upon request, and the current return rate of $\sim 80 \%$ is very high. Physicians are encouraged to provide samples from all suitable patients; prior serum AAT level assessment is not mandatory as the laboratory in Warsaw provides complete testing. Diagnostic tests performed include determination of AAT levels on dry blood spot samples, phenotyping, genotyping and, if required, DNA sequencing. After 4 years (2010 to June 2014) almost 2500 patients have been screened and, in this cohort, $\sim 13 \%$ had AATD alleles (fig. 2a). The majority of patients with AATD in this population were $\mathrm{PI}^{\star} \mathrm{ZZ}$ homozygotes (fig. 2b). An interesting finding from this screening programme was the number of patients with the $\mathrm{F}$ allele, the majority of whom originate from the north-eastern region of Poland and are being monitored further. Overall, in this population of patients with confirmed chronic obstructive pulmonary disorders, the detection frequency for $\mathrm{S}$ and $\mathrm{Z}$ alleles was four times that of the general population in Poland while the frequency of homozygous $\mathrm{PI}^{\star} \mathrm{ZZ}$ was 16 times that of the general population (table 1).
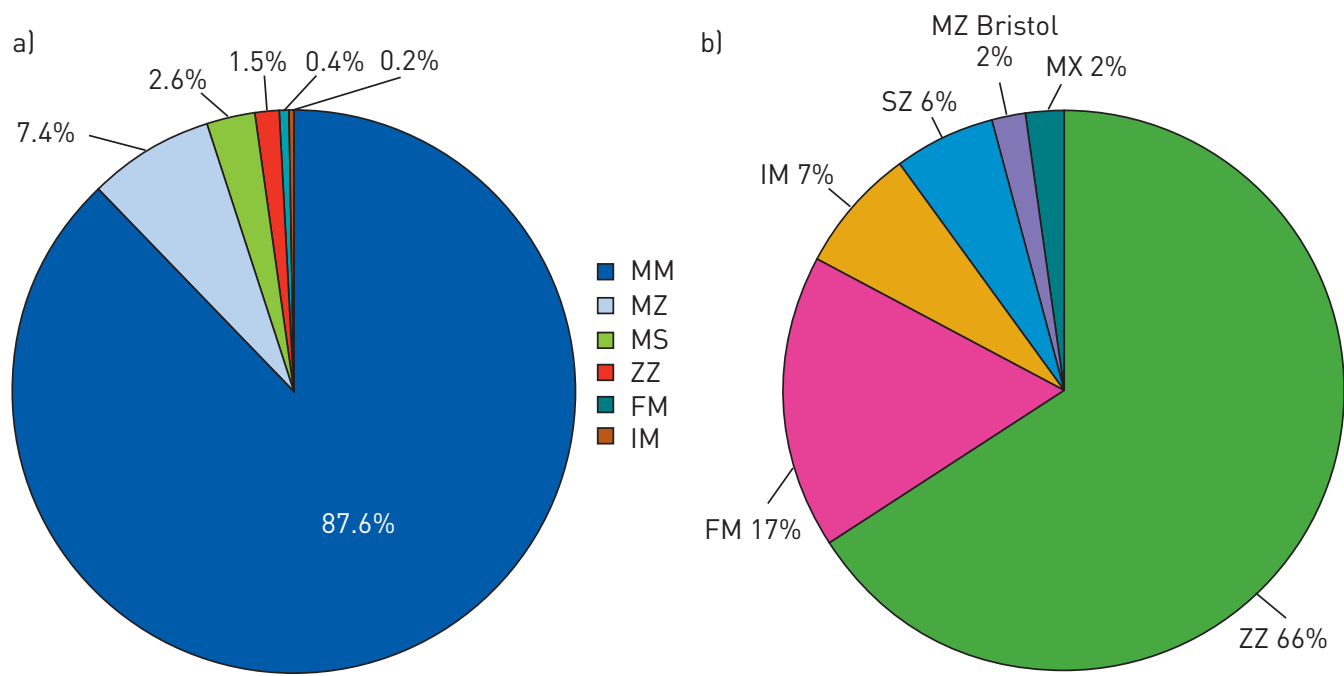

FIGURE 2 a) Findings from a targeted $\alpha_{1}$-antitrypsin deficiency (AATD) screening programme in Poland (2010 to June 2014) involving 2499 patients with confirmed chronic obstructive pulmonary disorders. $\mathrm{PI}^{\star} \mathrm{SZ}, \mathrm{PI}^{\star} \mathrm{MZbristol}$ and $\mathrm{PI}^{\star} \mathrm{MX}$ (each 0.1\%) are not shown the figure. b) The distribution of different genotypes in AATD patients. 
TABLE 1 Prevalence of $\alpha_{1}$-antitrypsin (AAT) genotypes in patients with confirmed chronic obstructive pulmonary disorders referred to the targeted screening programme in Poland: 2010 to June 2014

Estimated genotype frequency

AAT serum concentration $\mathrm{mg} \cdot \mathrm{dL}^{-1}$

\begin{tabular}{lcc}
\hline MM & $1 / 1.14$ & $166.4 \pm 44$ \\
MZ & $1 / 12$ & $97.2 \pm 36.3$ \\
MS & $1 / 38$ & $137.5 \pm 23.9$ \\
ZZ & $1 / 470$ & $25.9 \pm 6.4$ \\
FM & $1 / 212$ & $154 \pm 25.7$
\end{tabular}

Data are presented as $1 /$ Hardy-Weinberg or mean \pm SD.

These rates highlight the benefits of screening a targeted well-defined population. In terms of clinical presentation, the average age of our patients (49.9 years) was similar to that reported in studies from Italy, Germany and Spain (45-49 years) and COPD was the most frequent diagnosis (fig. 3) [19, 20].

Prior to the start of the screening programme in Poland, awareness levels of AATD in the medical community were very low. To improve this situation we started an awareness campaign based upon the Polish Respiratory Society National guidelines which were published in 2010 [21]. The guidelines were distributed to several thousand physicians across Poland, along with educational leaflets explaining how to screen for AATD and the relative simplicity of the procedure. Figure 4 shows the relative success of the campaign in terms of the number of samples sent to our laboratory for AAT testing from the various regions of Poland. Clearly more work is required in many areas of Poland to increase physician awareness of AATD. Based upon our experience overall, a successful targeted screening programme requires well-defined inclusion criteria, an efficient and cost-effective diagnostic algorithm, a strategy to increase physician awareness of AATD, and a dedicated hard-working team that is driven by success.

\section{Central Eastern Europe}

As noted previously, central Eastern Europe lags behind Western Europe with regards to diagnosis and screening for AATD. In 2011 experts from Poland (which is taking active steps to change this situation) were joined by experts from Lithuania, Slovakia, Romania, Bulgaria, Italy, the Netherlands and Germany in a European Union funded project [22]. The goal was to provide participating centres from central Eastern Europe with the "know-how" to enable them to implement effective diagnostic and screening programmes

FIGURE 3 Clinical presentation of $\mathrm{PI}^{\star} \mathrm{ZZ}$ homozygous patients identified during a targeted screening programme in Poland (2010 to June 2014). COPD: chronic obstructive pulmonary disease.

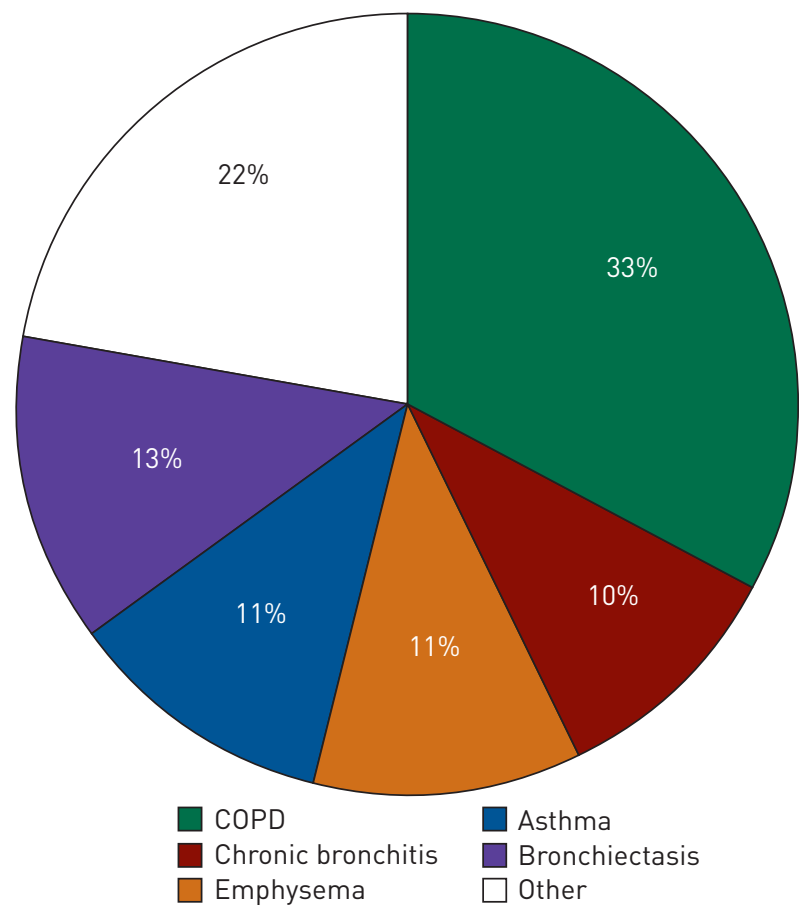




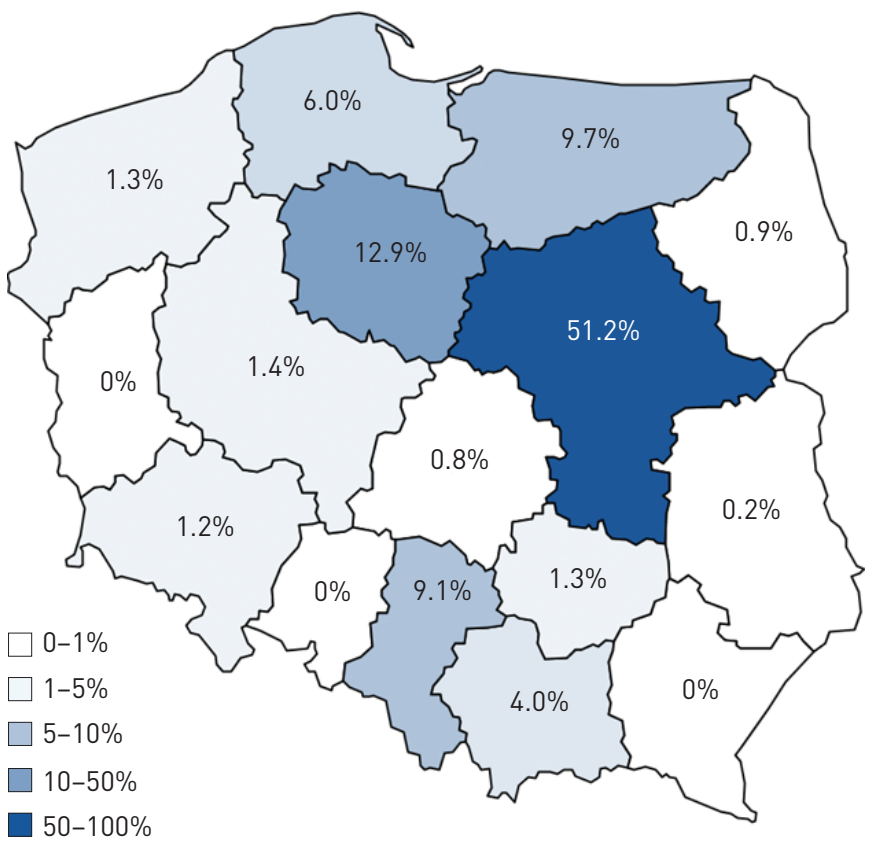

FIGURE $\quad 4 \quad \alpha_{1}$-antitrypsin deficiency awareness in Poland as estimated by the number of samples referred to the $\alpha_{1}$-antitrypsin diagnostic laboratory (\% of the total) within the targeted screening programme (2010 to June 2014).

for patients with AATD. The initiative involved workshops covering practical details, clinical issues and laboratory procedures, and also personal medical training for physicians, physiotherapists and nurses. Educational materials have been developed into local languages for the use of respiratory professionals, not just physicians, and we have helped create awareness programmes for AATD and patient needs in each of the countries. In addition to developing core skills for screening and diagnosing AATD, a primary goal of this project was to create the Central Eastern European Alpha-1 Antitrypsin Network at both the national and regional level; a goal which was achieved in 2013 [23]. A 2014 update by the Network confirmed the variability in frequency of AATD alleles in COPD patients across several countries in central Eastern Europe (table 2) [18]. Warsaw is a reference laboratory for these programmes and the network continues to grow. It has been joined by centres in Western and Eastern Ukraine and collaborations are also in place with Russia and Belarus.

\section{Conclusion}

To increase awareness of AATD in the medical community a better understanding of its prevalence and genetic distribution is essential. Equally important is the need for a better understanding of the role of $\mathrm{S}, \mathrm{Z}$ and rare mutations since this will guide the selection of appropriate disease management strategies. First and foremost is the need for efficient screening programmes and prompt and accurate diagnosis of AATD. Once this has been achieved we will be in a position to institute primary preventive measures, such as smoking cessation and avoidance of environmental and occupational exposure, and secondary prevention

TABLE 2 Estimated $\alpha_{1}$-antitrypsin (AAT) deficiency PI*S and $\mathrm{PI}$ *Z gene frequency in 1203 patients with chronic obstructive pulmonary disease referred to targeted screening within the central Eastern European Alpha-1 Antitrypsin Network programme: 2013 to June 2014

\section{Estimated AAT genotype frequency}

\section{PI*S}

\section{Bulgaria}

Lithuania

Poland

Romania

Slovakia

Mean
$47.6(-16.8-112)$
$19.2(11.3-27.2)$
$19.6(9.7-29.4)$
$13.1(0.3-25.8)$
$17.9(11.6-24.1)$

$20.3(-2.4-43)$

47.2 (34.9-59.5)

$14.4(5.9-22.8)$

$13.1(0.3-25.8)$

30.6 (22.5-38.7)

Data are presented as frequency $(95 \% \mathrm{CI})$. Frequency was calculated as $1 /$ Hardy-Weinberg. Data from [18]. 
through the treatment of related lung disease and augmentation therapy. In the past, countries in central Eastern Europe, such as Poland, have lagged behind the USA and Western European countries with regard to screening and diagnostic initiatives. With the creation of the Central Eastern European Alpha-1 Antitrypsin Network we are now accumulating rigorous epidemiological data and creating levels of expertise that will improve the identification and management of patients at high risk of developing COPD and other diseases.

\section{Acknowledgements}

Writing assistance was provided by Content Ed Net (Madrid, Spain) with funding from Grifols (Barcelona, Spain).

\section{References}

1 Luisetti M, Seersholm N. Alpha1-antitrypsin deficiency. 1: epidemiology of alpha1-antitrypsin deficiency. Thorax 2004; 59: 164-169.

2 Carroll TP, O'Connor CA, Floyd O, et al. The prevalence of alpha-1 antitrypsin deficiency in Ireland. Respir Res 2011; 12: 91.

3 Silverman EK, Sandhaus RA. Clinical practice. Alpha1-antitrypsin deficiency. N Engl J Med 2009; 360: 2749-2757.

4 Blanco I, de Serres FJ, Cárcaba V, et al. Alpha-1 antitrypsin deficiency $\mathrm{PI}^{\star} \mathrm{Z}$ and $\mathrm{PI}^{\star} \mathrm{S}$ gene frequency distribution using on maps of the world by an inverse distance weighting (IDW) multivariate interpolation method. Hepat Mon 2012; 12: e7434.

5 Campos MA, Lascano J. $\alpha 1$ Antitrypsin deficiency: current best practice in testing and augmentation therapy. Ther Adv Respir Dis 2014; 8: 150-161.

6 Stoller JK, Brantly M. The challenge of detecting alpha-1 antitrypsin deficiency. COPD 2013; 10: Suppl. 1, 26-34.

7 de Serres F. Worldwide racial and ethnic distribution of alphal-antitrypsin deficiency: summary of an analysis of published genetic epidemiologic surveys. Chest 2002; 122: 1818-1829.

8 Kaczor MP, Sanak M, Libura-Twardowska M, et al. The prevalence of alpha ${ }_{1}$-antitrypsin deficiency in a representative population sample from Poland. Respir Med 2007; 101: 2520-2525.

9 Chorostowska-Wynimko J, Górecka D, Sliwiński P, et al. "EUROPEAN COPD AUDIT" w Polsce - jak leczymy chorych z zaostrzeniem POCHP? [EUROPEAN COPD AUDIT in Poland - how do we treat the patients with COPD exacerbation?]. Pneumonol Alergol Pol 2012; 80: 493-497.

10 Chorostowska-Wynimko J, Struniawski R, Popławska B, et al. The incidence of alpha-1-antitrypsin (A1AT) deficiency alleles in population of Central Poland - preliminary results from newborn screening. Pneumonol Alergol Pol 2012; 80: 450-453.

11 Chorostowska-Wynimko J, Struniawski R, Poplawska-Wisniewska B, et al. The incidence of alpha-1-antitrypsin (A1AT) deficiency alleles in Polish population - results from large scale newborn screening. Eur Respir J 2014; 44: Suppl. 58, P2036.

12 Alpha 1-antitrypsin deficiency: memorandum from a WHO meeting. Bull World Health Organ 1997; 75: 397-415.

13 American Thoracic Society, European Respiratory Society. American Thoracic Society/European Respiratory Society statement: standards for the diagnosis and management of individuals with alpha- 1 antitrypsin deficiency. Am J Respir Crit Care Med 2003; 168: 818-900.

14 Wencker M, Marx A, Konietzko N, et al. Screening for $\alpha_{1}$-Pi deficiency in patients with lung diseases. Eur Respir $J$ 2002; 20: 319-324.

15 de la Roza C, Rodríguez-Frías F, Lara B, et al. Results of a case-detection programme for $\alpha 1$-antitrypsin deficiency in COPD patients. Eur Respir J 2005; 26: 616-622.

16 Bals R, Koczulla R, Kotke V, et al. Identification of individuals with alpha-1-antitrypsin deficiency by a targeted screening program. Respir Med 2007; 101: 1708-1714.

17 Górska K, Korczyński P, Struniawski R, et al. Heterozygous alpha-1 antitrypsin deficiency in patients evaluated as live transplant condidates. Pol Arch Int Med 2013; 123: 14-20.

18 Chorostowska-Wynimko J, Kubincova A, Yanev N, et al. The incidence of severe alpha-1-antitrypsin (AAT) deficiency alleles in COPD patients - update from Central Eastern European (CEE) AAT Network. Eur Respir J 2014; 44: Suppl. 58, P2035.

19 Köhnlein T, Janciauskiene S, Welte T. Diagnostic delay and clinical modifiers in alpha-1 antitrypsin deficiency. Ther Adv Respir Dis 2010; 4: 279-287.

20 Piras B, Ferrarotti I, Lara B, et al. Clinical phenotypes of Italian and Spanish patients with $\alpha_{1}$-antitrypsin deficiency. Eur Respir J 2013; 42: 54-64.

21 Chorostowska-Wynimko J, Nizankowska-Mogilnicka E, Grupa Robocza Polskiego Towarzystwa Chórob Płuc, et al. Zasady postepowania diagnostycznego i opieki nad chorymi $\mathrm{z}$ wrodzonym niedoborem alfa-1 antytrypsyny [Diagnosis and treatment of patients with alpha-1 antitrypsin (alpha-1 AT) deficiency]. Pneumonol Alergol Pol 2010; 78: 348-355.

22 Chorostowska-Wynimko J. Introducing standards of the best medical practice for patients with inherited alpha- 1 antitrypsin deficiency in Central Eastern Europe. www.europeansharedtreasure.eu/detail.php?id_project_base= 2011-1-PL1-LEO04-19715 Date last accessed: January, 2015.

23 Chorostowska-Wynimko J. Wiara czyni cuda - Srodkowo-Wschodnioeuropejska Siec Alfa-1 Antytrypsyny [Believe in miracles - Central-Eastern European Alpha-1 Antitrypsin Network]. Pneumonol Alergol Pol 2013; 81: 285-287. 